Review

\title{
Surgical Algorithm for Obstructive Sleep Apnea: An Update
}

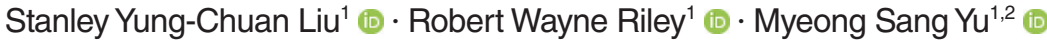 \\ ${ }^{I}$ Division of Sleep Surgery, Department of Otolaryngology-Head and Neck Surgery, Stanford University School of Medicine, Stanford Hospital \\ and Clinics, Stanford, CA, USA; ${ }^{2}$ Department of Otorhinolaryngology-Head and Neck Surgery, Asan Medical Center, University of Ulsan College \\ of Medicine, Seoul, Korea
}

\begin{abstract}
Sleep surgery is part of a continuum of care for obstructive sleep apnea (OSA) that involves medical, pharmacologic, and behavioral therapy. Upper airway surgery for OSA can significantly improve stability by way of modulating the critical negative closing pressure. This is the same mechanism of action as positive airway pressure or oral appliance therapy. The updated surgical algorithm in this review adds precision in three areas: patient selection, identification of previously unaddressed anatomic phenotypes with associated treatment modality, and improved techniques of previously established procedures. While the original Riley and Powell phase 1 and 2 approach to sleep surgery has focused on individual surgical success rate, this algorithm strives for an overall treatment success with multi-modal and patient-centric treatments.
\end{abstract}

Keywords. Obstructive Sleep Apnea; Sleep Surgery; Palatopharyngoplasty; Algorithm; Maxillomandibular Advancement; Hypoglossal Nerve Stimulation; Upper Airway Stimulation

\section{INTRODUCTION}

Sleep surgery has come a long way in the three decades since the advent of the original phase 1 and 2 Stanford algorithm by Riley and Powell [1]. Phase 1 involves multi-level surgery including tonsillectomy and uvulopalatal flap with genioglossus advancement (GA) [1,2]. Inadequate responders to phase 1 are recommended phase 2 surgery: maxillomandibular advancement (MMA) [3]. This protocol compared favorably to positive airway pressure (PAP) therapy, especially with the inclusion of MMA [4]. The drawback to the algorithm is its unidirectional nature. It assumes that obstructive sleep apnea (OSA) does not recur if a cure, defined as Apnea Hypopnea Index (AHI) less than five events per hour, is achieved at one point. It also does not take into account patient preferences of elective procedures.

\footnotetext{
- Received June 8, 2020

Revised June 29, 2020

Accepted June 29, 2020

- Corresponding author: Myeong Sang Yu

Department of Otorhinolaryngology-Head and Neck Surgery, Asan Medical Center, University of Ulsan College of Medicine, 88 Olympic-ro 43-gil, Songpa-gu, Seoul 05505, Korea

Tel: +82-2-3010-3710, Fax: +82-2-489-2773

E-mail: dryums@gmail.com
}

Finally, it does not incorporate multi-modal treatment such as PAP and oral appliance therapy (OAT).

Sleep surgery is part of a continuum of care for OSA that involves medical, pharmacologic, and behavioral therapy. Upper airway surgery for OSA may not alter arousal threshold, loop gain, or muscle tone. It can, however, significantly change the critical negative closing pressure [5].This is the same mechanism of action as PAP or OAT. The updated surgical algorithm adds precision in three areas: (1) patient selection, (2) identification of previously unaddressed anatomic phenotypes, and (3) surgical techniques [6,7]. Conceptually, while the focus has been on individual surgical success rate, this algorithm strives for an overall treatment success. The growing understanding of the pathophysiology of OSA and development of new methods for airway evaluation allow improved phenotyping of the upper airway and customization of surgical treatment. This review provides an update the original surgical algorithm for OSA.

\section{PATIENT SELECTION}

Precise phenotyping of patients with polysomnographic findings, targeted physical examination, and diagnostic tools are critical

Copyright (C) 2020 by Korean Society of Otorhinolaryngology-Head and Neck Surgery.

This is an open-access article distributed under the terms of the Creative Commons Attribution Non-Commercial License (https://creativecommons.org/licenses/by-nc/4.0)

which permits unrestricted non-commercial use, distribution, and reproduction in any medium, provided the original work is properly cited. 

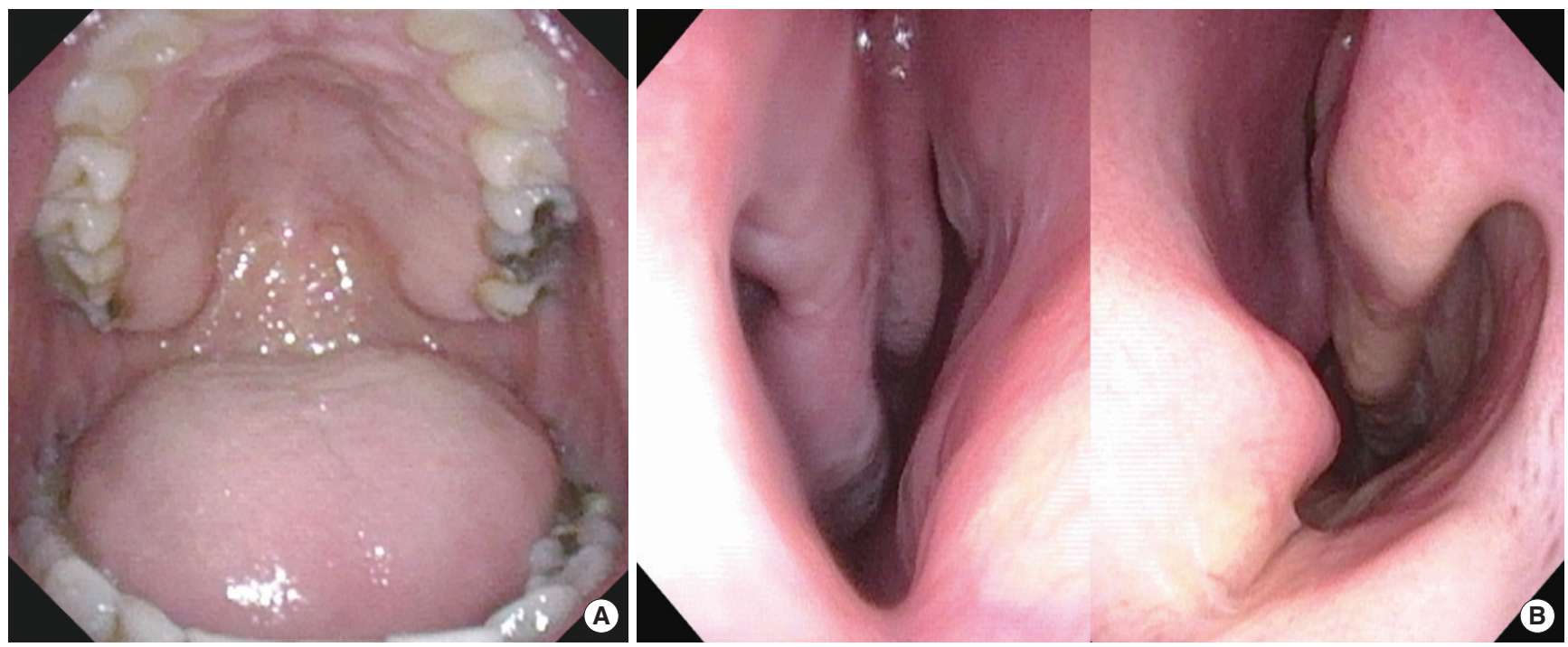

Fig. 1. Obstructive sleep apnea patient with high-arched palate $(A)$ and narrow nasal floor (B). Narrow and high-arched hard palate indicates a disproportion between the volume of tongue and the size of the oral cavity.

to optimizing surgical success in patients with OSA. Sleep surgeons should consider the patient's preferences, expectations, associated comorbidities, OSA severity, and individual anatomy.

\section{Physical examination}

A meticulous sleep-specific history, full head and neck examination including the nasal airway, velopharynx, pharyngeal wall, tongue base, and epiglottis, and facial skeletal relationship should be performed to facilitate surgical planning [6]. Nasal obstruction may be the main cause of PAP intolerance [8,9]. Therefore, care should be taken to assess anatomical abnormalities causing nasal obstruction, including posterior septal deviation $[10,11]$. Exam should involve endoscopic examination to

\section{H I G H L I G H T S}

- The growing understanding of the pathophysiology of obstructive sleep apnea (OSA) and development of new methods for airway evaluation allow improved phenotyping of the upper airway and customization of surgical treatment.

- Dynamic airway assessment has been augmented with examination under drug-induced sedation (sleep) endoscopy.

- Conceptually similar to pediatric rapid maxillary expansion, distraction osteogenesis maxillary expansion effectively addresses the same anatomic phenotype in adults.

- Maxillomandibular advancement and upper airway stimulation have been highly effective surgical options for the treatment of OSA, but they differ in strengths and limitations, and may complement each other.

- The combination of contemporary sleep surgery with advances in modulation of arousal threshold, loop gain, and muscle tone will truly define precision in OSA care. identify all possible anatomic and functional causes of nasal obstruction [10]. While there is only modest correlation between the severity of disease and grading of airway collapse during Muller's maneuver, the negative pressure maneuver is a quick method to assess upper airway collapsibility [12]. A mandibular protrusion maneuver can be performed at the same time to visualize the degree of lateral pharyngeal wall dilation and tongue base advancement. Nasal examination is not limited to the nose alone. Long-term nasal obstruction leads to facial changes, most often in the appearance of a long midface, open bite, and retruded mandible. Intraoral examination tends to show narrow, high-arch maxilla with the appearance of a relatively large tongue and redundant soft palatal tissue (Fig. 1). This is the classic adenoid facies associated with chronic mouth breathing [1315]. The internal nasal valve (INV), the most restrictive part for nasal airflow, is a target for intervention. The INV includes the septum, the inferior turbinates, the upper lateral cartilage, and the nasal floor.

\section{Polysomnography}

Overnight polysomnography (PSG) is the gold standard for diagnosing and evaluating the severity of OSA, although it may not reflect a patient's status over a long period of time [16]. The severity of OSA is measured by the AHI. Beyond the AHI, oxygen desaturation nadir also reflects the severity of OSA. Some studies have shown that the oxygen desaturation index correlates more strongly with cardiovascular morbidity of OSA than the AHI alone $[17,18]$. Recently, ambulatory sleep study is increasingly replacing level 1 PSG. It must be noted that ambulatory sleep testing tends to underestimate OSA severity [19-21]. Surgical success should be compared using the same diagnostic study and hypopnea criteria before and after surgery $[6,22]$. 


\section{Drug-induced sleep endoscopy}

Various diagnostic tools including cephalometric X-ray [23], awake flexible laryngoscope [24], acoustic analysis [25], computed tomography (CT) scan [26], and dynamic magnetic resonance imaging [27] have been introduced to identify and phenotype the upper airway anatomy among OSA patients. However, most airway assessment techniques are performed in the awake and static state, which does not reflect sleep-disordered breathing [28]. Dynamic airway assessment has been augmented with examination under drug-induced sedation (sleep) endoscopy (DISE) $[29,30]$. DISE is a useful tool to visualize and phenotype this pharyngeal muscle buttress system that varies in length, lateral dimension, antero-posterior diameter, and structural elements, and is influenced by the skeletal structure within which it is located [28].

There is no consensus regarding standardized protocols for DISE. The procedure is usually performed in the supine position in an outpatient surgery setting with monitoring of oxygen saturation, heart rate, blood pressure, and sometimes, Bispectral index score. Propofol, dexmedetomidine, and midazolam are commonly used for induction of sedation. Propofol has the benefit of rapid onset of action and recovery with minimal side effects [31]. The genioglossus muscle tone is decreased by up to $10 \%$ of the maximum awake activity in healthy individuals during propofol unconscious sedation $[32,33]$. Currently, the effect of midazolam and dexmedetomidine on genioglossus muscle tone is unknown [34]. Midazolam has a greater therapeutic range but is limited by its slow onset and potential to cause respiratory depression. Dexmedetomidine has the characteristics of rapid onset and small therapeutic range, with less respiratory side effects [35]. The depth of sedation is critical and evaluated by the onset of disordered breathing or the Bispectral index score [32].

Several classification systems have been introduced to characterize DISE findings [36-40]. The VOTE classification system, comprised of the Velum, Oropharyngeal (lateral walls), Tongue, and Epiglottis, is widely used for DISE scoring. The most common finding from DISE is multilevel collapse, despite heterogeneity among studies $[41,42]$. The patterns of complete concentric collapse (CCC), multilevel collapse, and tongue base collapse are associated with higher AHI [41,42]. CCC has been associated with poor surgical outcomes in multilevel surgery and upper airway stimulation (UAS) [43,44], but is well-addressed by MMA [45].

\section{SURIGICAL PROCEDURES FOR OSA: ORGANIZED BY SITE}

\section{Intranasal surgery: septoplasty, turbinoplasty, nasal valve surgery}

Nasal breathing is an important factor for sleep quality, and nasal obstruction does contribute to the pathogenesis of OSA [46,
47]. Septal deviation, turbinate hypertrophy, and valve dysfunction can result in increased nasal resistance and subsequent mouth breathing. Increased nasal resistance leads to downstream inspiratory collapse of the oropharynx or hypopharynx in susceptible OSA patients $[48,49]$. Mouth breathing can also cause posterior displacement of the base of the tongue and consequent narrowing of the hypopharyngeal airway [7]. Nasal surgery including septoplasty, turbinoplasty, or valve reconstruction can restore nasal airway patency and reduce nasal resistance and mouth breathing. Although nasal surgery alone shows limited efficacy in terms of AHI [50], it improves sleep quality, OSA-related sleep symptoms, and PAP compliance [51-53]. Nasal surgery is important in the multilevel treatment plan for OSA [54].

\section{Nasal floor expansion: distraction osteogenesis maxillary expansion}

Expansion of the adult nasal floor is useful for OSA patients who present with narrow and high-arch maxilla [15]. Patients with this phenotype tend struggle with both nasal obstruction and lack of intraoral volume for the tongue during sleep. Maxillary expansion directed at the nasal floor by way of distraction osteogenesis with maxillary expansion (distraction osteogenesis maxillary expansion [DOME]) has shown promise [55-58]. Minimally invasive osteotomies can be made at the LeFort I level via an intranasal incision. An expander is anchored to the roof of maxilla intraorally. The patient turns the expander once a day, which translates to an expansion of $0.025 \mathrm{~mm}$. This generally results in 8 to $10 \mathrm{~mm}$ of widened nasal floor at the INV in a month (Fig. 2). Orthodontic treatment restores the occlusion. Conceptually similar to pediatric rapid maxillary expansion, DOME effectively addresses the same anatomic phenotype in adults [58-62].

\section{Oropharynx: uvulopalatopharyngoplasty}

Uvulopalatopharyngoplasty (UPPP) remains the most commonly performed sleep surgical procedure worldwide [63]. Most surgeons specialized in OSA have stopped performing earlier methods of UPPP, which tend to be ablative in nature including resection of the uvula. This is particularly true in procedures such as the laser-assisted UPPP which worsens AHI in $44 \%$ of patients based on meta-analysis [64]. Isolated soft palate surgery has the highest success rate in Friedman stage I patients [38]. In clinical practice, various forms of UPPP are often performed as part of multi-level surgery to maximize surgical success $[1,65,66]$. In the Riley-Powell sleep surgery algorithm, uvulopalatal flap is part of multi-level surgery with GA during phase 1 . The uvulopalatal flap was designed as a reversible soft palate procedure in the event of velopharyngeal insufficiency [2]. Most forms of contemporary UPPP focus on palatal muscle expansion and stabilization with targeted vectors during suturing [67-70].

Various techniques of palatopharyngoplasty such as lateral pharyngoplasty, expansion sphincter pharyngoplasty, and 

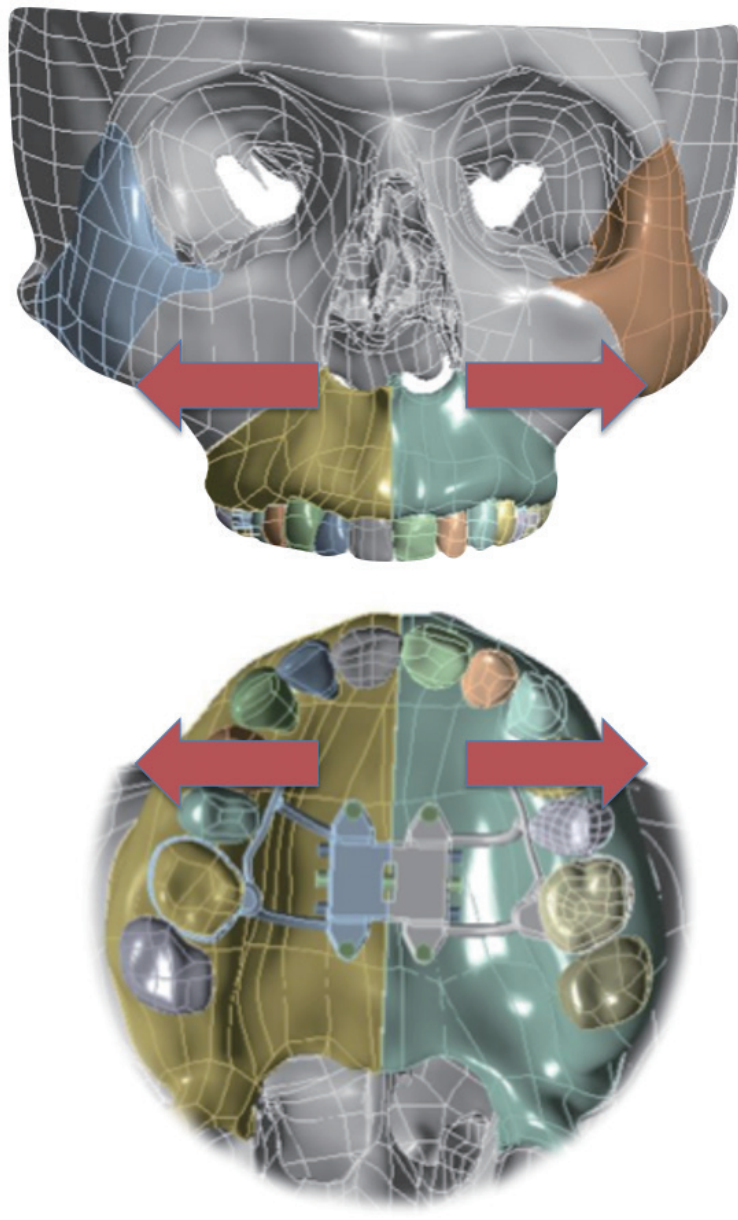

Fig. 2. Distraction Osteogenesis Maxillary Expansion: maxillary expansion results in widening of nasal floor and internal nasal valve.

transpalatal advancement pharyngoplasty have been introduced to resolve the limitations of classic UPPP. Collectively, they have shown more successful outcomes than the classic UPPP [28,7175]. Sleep surgeons can individualize the options according to the pattern of collapse. For example, lateral pharyngoplasty, expansion sphincter pharyngoplasty, or similar procedures can be applied to lateral pharyngeal collapse, while transpalatal advancement pharyngoplasty can be utilized in anteroposterior narrowing [76].

An indication for isolated UPPP is part of a phased approach towards UAS. CCC of the soft palate (velum) seen during DISE is an exclusion criteria for UAS, palatopharyngoplasty can reverse this collapse pattern and increase candidacy for UAS [77].

\section{Tongue base: lingual tonsillectomy, transoral robotic surgery}

Untreated retrolingual obstruction is well recognized as a major cause of surgical failure [78]. Removal of the lingual tonsils and base of tongue fat may involve the use of coblation, laser, or robotic assistance per surgeon preference [79-81]. The removal of tissue in this area can be supplemented by an anterior anchor-

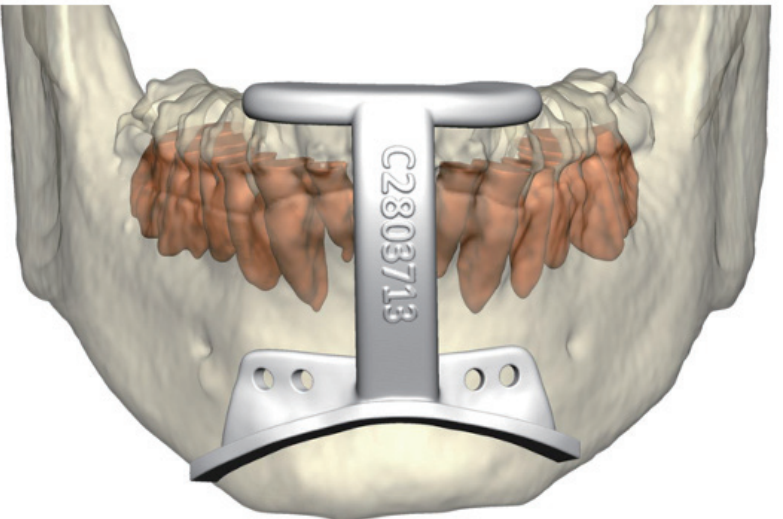

Fig. 3. Virtual surgical planning of genioglossus advancement: the osteotomy guide is designed to capture the genial tubercle.

age of the epiglottis to the base of tongue for epiglottis collapse. With high quality optics for improved visualization and instrumentation, robotics was adapted and introduced to target the posterior tongue $[81,82]$. While transoral robotic surgery (TORS) offers unparalleled visualization, the use of multi-armed robots originally designed for the abdominal cavity can be cumbersome for the upper airway. Results for the use of TORS as part of a multilevel surgical approach for OSA are promising for select patients. Success rate of TORS was higher than $75 \%$ in nonobese patients and $50 \%$ in obese patients with OSA [83].

The cost and morbidity may be greater than with other techniques offsetting its advantages in visualization and precision [84]. On comparing the surgical outcomes between TORS $(n=820)$ and coblation $(n=262)$, the mean rate of failure was found to be $34.4 \%$ in TORS and $38.5 \%$ in the coblation group. The postoperative complication rates were $21.3 \%$ and $8.4 \%$ [85]. The advent of single port robot system which is designed for single cavity operative sites is promising [86]. Augmented reality assisted TORS using a single-port robot will reduce morbidity such as bleeding and increase precision in distinguishing fat from muscle [87].

\section{Tongue muscle strengthening: genioglossus advancement}

Classic GA was designed by Powell and Riley as part of phase 1 algorithm. GA is usually performed in conjunction with other procedures (UPPP, MMA) [88]. The genioglossus muscle, a powerful dilator muscle of the upper airway, is attached to the genial tubercles. In advancing the genial tubercles, the genioglossus muscle strengthens over time and allows greater tongue advancement during sleep [89]. With the wide availability of CT scan, virtual surgical planning and osteotomy guides allow contemporary GA to be considerably more precise (Fig. 3) [90]. GA and genioplasty can often be performed in conjunction to improve facial balance in retrognathic patients [91].This combination also exerts strengthening effects on suprahyoid muscles. 

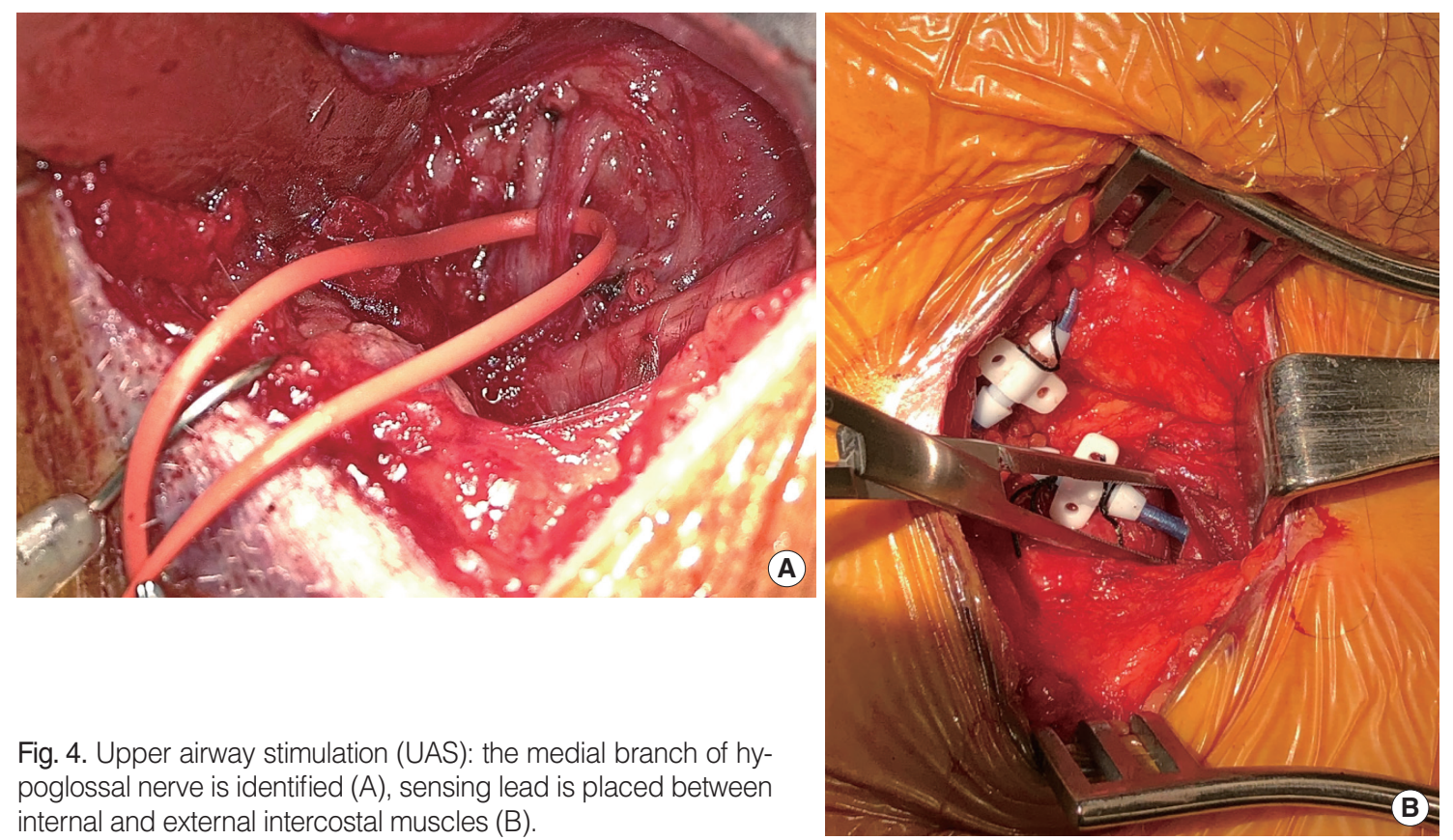

Fig. 4. Upper airway stimulation (UAS): the medial branch of hypoglossal nerve is identified $(A)$, sensing lead is placed between internal and external intercostal muscles (B).

creased after UAS. There are no significant changes to rapid eye

Tongue: upper airway stimulation

At the time of publication, there is only one Food and Drug Administration-approved UAS device (Inspire Medical Systems, Maple Grove, MN, USA) for OSA. It generates a unilateral respiration-synchronized stimulation of the medial hypoglossal nerve branches and $\mathrm{C} 1$ nerve, leading to tongue stiffening and protrusion during sleep via the genioglossus and geniohyoid muscles (Fig. 4). The hypoglossal nerve (CN XII) innervates both the tongue protrusor (genioglossus) and retrusor (styloglossus and hyoglossus) muscles through its medial and lateral divisions. Selective stimulation of the protrusor muscles leads to anterior movement of the tongue, resulting in increased airflow and reduced pharyngeal collapse during sleep [92]. Selective stimulation of the deep and horizontally oriented genioglossus fibers results in curling and stiffening of the tongue, further expanding the upper airway [93].

The current selection criteria requires DISE to rule out CCC of the velum. There is a body mass index (BMI) requirement of $32 \mathrm{~kg} / \mathrm{m}^{2}$ and below, and an AHI range from 15 to 65 . There is a $25 \%$ cutoff for central apneas. Implanted patients undergo inlab titration of UAS approximately 2 months after implantation.

The Stimulation Therapy for Apnea Reduction (STAR) trial found UAS to be successful with a median decrease of $68 \%$ in AHI [94]. Recent meta-analyses show that UAS is a safe and effective for selected patients with moderate to severe OSA [95]. A study including 102 patients revealed that $22.6 \%$ of the patients used UAS therapy for less than 4 hours per night, $77.4 \%$ for 4 hours or more per night, and $55.7 \%$ of the patients for more than 6 hours per night [96]. UAS can improve AHI as well as sleep architecture in responders. Arousal index and N1 sleep were reduced while time spent in N2 and slow wave sleep in- movement (REM) sleep [97].

Total upper airway: maxillomandibular advancement

MMA is pioneered by Riley and Powell at Stanford Hospital in the late 1980's, and addresses the entire upper airway that can contribute to OSA. It remains one of the most effective surgical intervention for patients with OSA, and has compared favorably to continuous positive airway pressure (CPAP) in a variety of studies including a prospective, randomized controlled trial [1,3,4,89,98-101]. MMA involves osteotomies of the maxilla and mandible, followed by their advancement that is frequently accompanied with counterclockwise rotation (Fig. 5) [102,103]. The net effect includes greater volume for intraoral soft tissue structures and stability of the upper airway dilator muscles $[7,45,104,105]$. Generally, indications for MMA are : (1) moderate to severe OSA with our without history of phase 1 surgery, (2) OSA of all severity if there is comorbid dentofacial deformity, and (3) concentric and lateral pharyngeal wall collapse seen with DISE $[6,7,103]$. Age of patient and severity of OSA have not been shown to impact the technical aspects of MMA in a high volume center [106].

Meta-analysis by Holty and Guilleminault [107] examined 22 studies involving 627 patients who underwent MMA, reporting mean AHI decrease from 63.9 to 9.5 events per hour. The authors defined surgical success with the Sher criteria: a minimum of $50 \%$ reduction with a final AHI less than 20 .The surgical success rate was $86.0 \%$ and the cure rate $(\mathrm{AHI}<5)$ was $43.2 \%$. The predictive factors for surgical success were younger age, lower BMI, and greater degree of maxillary advancement. The major and minor complication rates were $1.0 \%$ and $3.1 \%$, respec- 

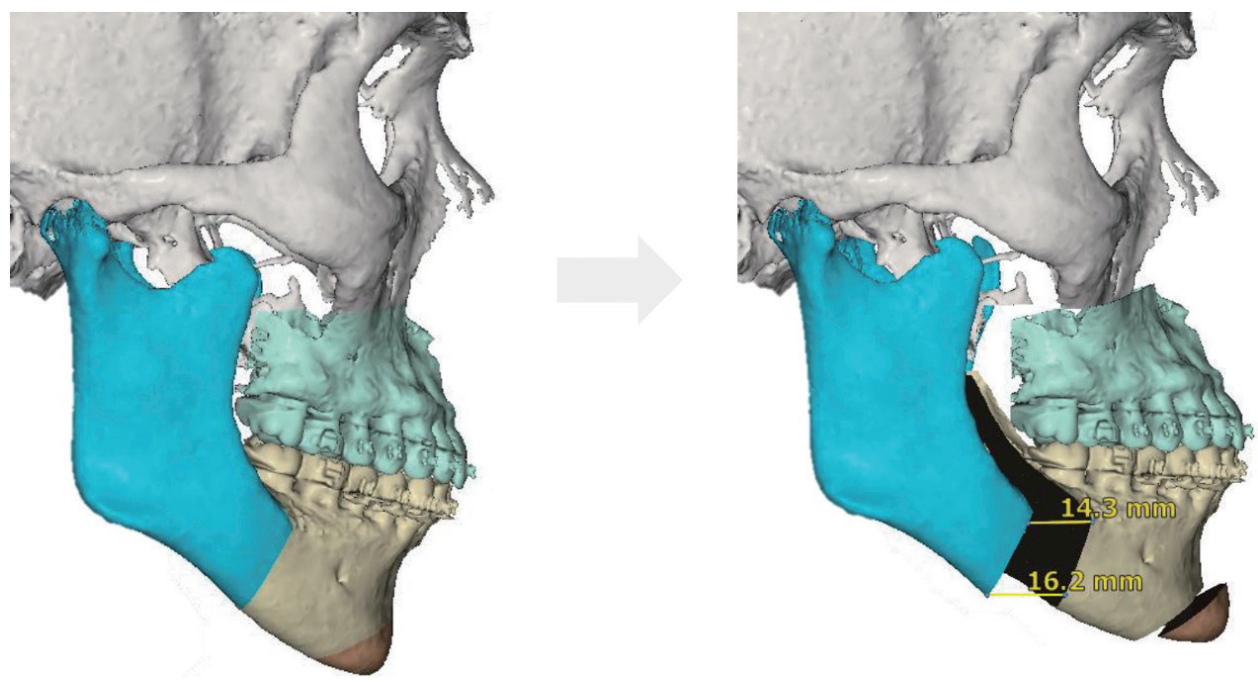

Fig. 5. Counterclockwise maxillomandibular advancement allows a greater advancement of mandible than maxilla, to maximize airway and facial esthetics.

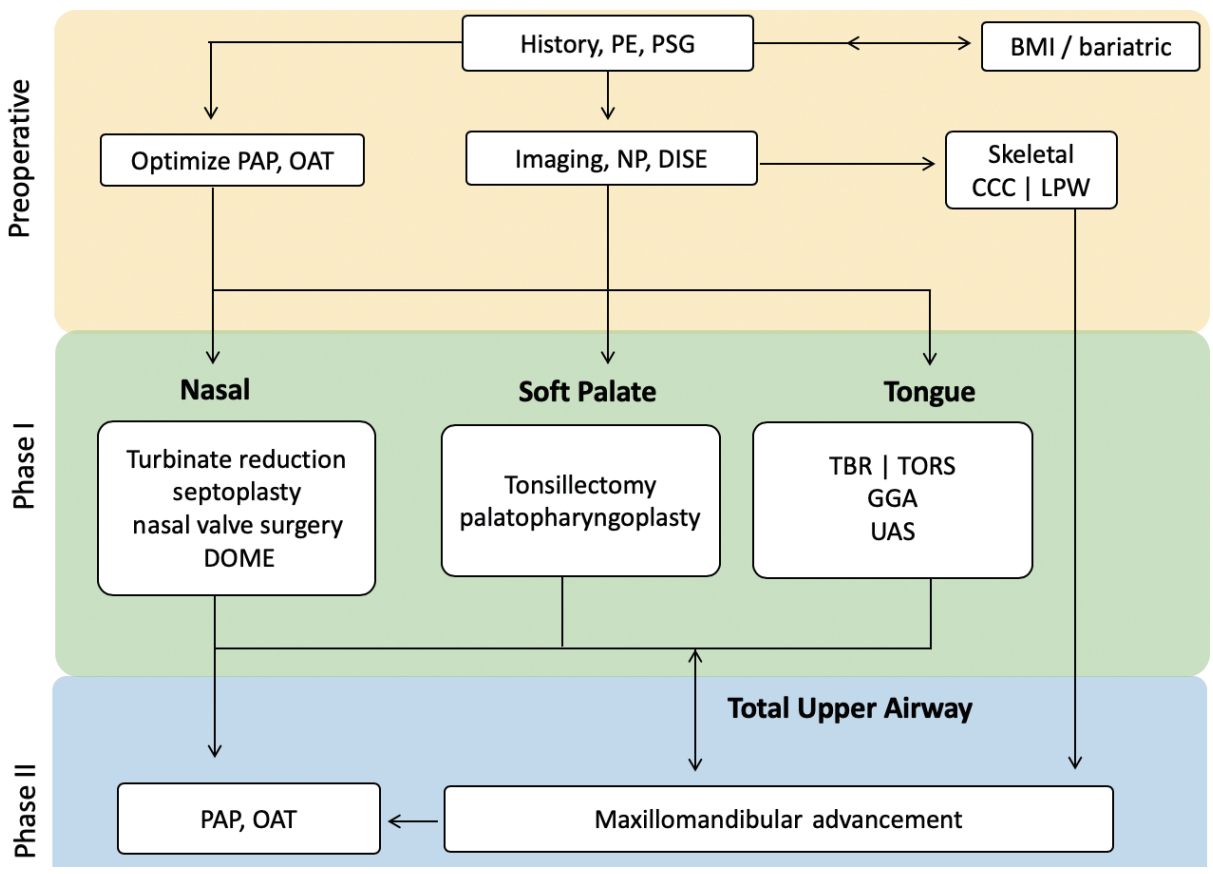

Fig. 6. Updated Stanford sleep surgery algorithm. PE, physical examination; PSG, polysomnography; BMI, body mass index; PAP, positive airway pressure; OAT, oral appliance therapy; NP, nasopharyngoscopy; DISE, drug-induced sedation (sleep) endoscopy; CCC, complete concentric collapse; LPW, lateral pharyngeal wall; DOME, distraction osteogenesis maxillary expansion; TBR, tongue base reduction; TORS, transoral robotic surgery; GGA, genioglossus advancement; UAS, upper airway stimulation.

tively. Zaghi et al. [108] updated the meta-analsysis with 45 studies and 528 patients reporting success and cure rates of $85.5 \%$ and $38 \%$, respectively. In 40 patients who underwent MMA with average follow-up of 4.2 years (range, 1 to 12 years), 36 patients $(90 \%)$ maintained a significant reduction in respiratory disturbance index from 71.2 to 7.6 events per hour with improvement in daytime sleepiness [109]. In another study with mean follow-up of 12.5 years, surgical success rate maintained at $100 \%$ in patients less than 45 years old, and who had BMI less than $25 \mathrm{~kg} / \mathrm{m}^{2}$ [110].

Beyond the AHI, MMA has shown normalization of sleep architecture (increase in REM sleep and decrease in wakefulness after sleep onset when compared to age-matched healthy controls [45]. It has also shown improvements in multiple health-related and functional outcomes [111]. 


\section{SURGICAL ALGORITHM: PATIENT-CENTERED, PATIENT FIRST}

Surgical algorithm for OSA considers anatomic abnormality, disease severity, and patient preference. The balance between these three factors and morbidity of surgery must be emphasized. Riley et al. [89] developed the original sleep surgery algorithm where soft tissue and skeletal framework were targets for intervention. The updated algorithm reflects the contemporary needs of improved precision on: (1) patient phenotyping, (2) new procedures to address distinct phenotypes, and (3) improved methods for previously established operations $[6,7,103]$. The updated algorithm is shown in Fig. 6.

In clinic, after a thorough history, physical exam, review of PSG, and nasopharyngoscopy, the first decision is made regarding optimization of PAP or OAT use. Of note, the efficacy of upper airway surgery for OSA begins to drop as BMI increases. Bariatric surgical evaluation and treatment should precede upper airway surgery in select candidates. Use of imaging or DISE to help determine treatment course is made judiciously on an individual basis, as they are supplemental tools.

MMA and UAS have been highly effective surgical options for the treatment of OSA. Both have shown predictably high success rates with low morbidity.They differ in strengths and limitations, and may complement each other. DISE is currently required to rule out CCC of the velum for UAS. Concentric collapse and lateral pharyngeal wall collapse from DISE are associated with low success rate of soft tissue surgery [112,113]. MMA is more reliable in reversing these collapse patterns [45,105]. MMA can also be a first-line consideration for patients with any degree of OSA with dentofacial deformity. If MMA is performed first, the patient is still eligible, and may need, phase 1 procedures. UAS or PAP following MMA relapse are safe options especially in patients with advanced age [114].

\section{CONCLUSION}

The growing understanding of OSA pathophysiology, new methods for airway anatomic phenotyping, and individualized surgical modalities optimize surgical management of OSA. As comprehensive as this updated algorithm directs surgical care, the most pressing need is its integration with physiologic phenotyping.. The combination of contemporary sleep surgery with advances in modulation of arousal threshold, loop gain, and muscle tone will truly define precision in OSA care.

\section{CONFLICT OF INTEREST}

No potential conflict of interest relevant to this article was reported.

\section{ORCID}

Stanley Yung-Chuan Liu

https://orcid.org/0000-0001-6885-7885

RobertWayne Riley https://orcid.org/0000-0002-0676-2757

Myeong Sang Yu https://orcid.org/0000-0002-4529-0254

\section{AUTHOR CONTRIBUTIONS}

Conceptualization: SYCL, MSY. Data curation: RWR, MSY. Formal analysis: SYCL, MSY. Methodology: all authors. Project administration: SYCL. Visualization: MSY. Writing-original draft: SYCL.Writing-review \& editing: SYCL, MSY.

\section{REFERENCES}

1. Riley RW, Powell NB, Guilleminault C. Obstructive sleep apnea syndrome: a surgical protocol for dynamic upper airway reconstruction. J Oral Maxillofac Surg. 1993 Jul;51(7):742-9.

2. Powell N, Riley R, Guilleminault C, Troell R. A reversible uvulopalatal flap for snoring and sleep apnea syndrome. Sleep. 1996 Sep; 19(7):593-9.

3. Riley RW, Powell NB, Guilleminault C, Nino-Murcia G. Maxillary, mandibular, and hyoid advancement: an alternative to tracheostomy in obstructive sleep apnea syndrome. Otolaryngol Head Neck Surg. 1986 Jun;94(5):584-8.

4. Riley RW, Powell NB, Guilleminault C. Maxillofacial surgery and nasal CPAP: a comparison of treatment for obstructive sleep apnea syndrome. Chest. 1990 Dec;98(6):1421-5.

5. Decker M, Yamauchi M, Strohl KP. Keep the airway open and let the brain sleep. Am J Respir Crit Care Med. 2014 Dec;190(11): 1207-9.

6. Liu SY, Awad M, Riley R, Capasso R. The role of the revised Stanford protocol in today's precision medicine. Sleep Med Clin. 2019 Mar;14(1):99-107.

7. Liu SY, Powell NB, Riley RW. Algorithm for multilevel treatment: the Riley, Powell, and Liu Stanford experience. In: Friedman M, Jacobowitz O, editors. Sleep apnea and snoring: surgical and non-surgical therapy. 2nd ed. Edinburgh: Elsevier; 2020. p. 104-9.

8. Zozula R, Rosen R. Compliance with continuous positive airway pressure therapy: assessing and improving treatment outcomes. Curr Opin Pulm Med. 2001 Nov;7(6):391-8.

9. Chervin RD, Theut S, Bassetti C, Aldrich MS. Compliance with nasal CPAP can be improved by simple interventions. Sleep. 1997 Apr;20(4):284-9.

10. Torre C, Capasso R, Zaghi S, Williams R, Liu SY. High incidence of posterior nasal cavity obstruction in obstructive sleep apnea patients. Sleep Sci Pract. 2017 Mar;1(1):8.

11. Camacho M, Zaghi S, CertalV, Abdullatif J, Means C, Acevedo J, et al. Inferior turbinate classification system, grades 1 to 4 : development and validation study. Laryngoscope. 2015 Feb;125(2):296-302.

12. Terris DJ, Hanasono MM, Liu YC. Reliability of the Muller maneuver and its association with sleep-disordered breathing. Laryngoscope. 2000 Nov;110(11):1819-23.

13. Huynh NT, Morton PD, Rompre PH, Papadakis A, Remise C. Associations between sleep-disordered breathing symptoms and facial and dental morphometry, assessed with screening examinations. Am J Orthod Dentofacial Orthop. 2011 Dec;140(6):762-70. 
14. Kim JH, Guilleminault C. The nasomaxillary complex, the mandible, and sleep-disordered breathing. Sleep Breath. 2011 May;15(2): 185-93.

15. Williams R, Patel V, Chen YF, Tangbumrungtham N, Thamboo A, Most SP, et al. The upper airway nasal complex: structural contribution to persistent nasal obstruction. Otolaryngol Head Neck Surg. 2019 Jul;161(1):171-7.

16. Goldberg AN. Obstructive sleep apnea: decision making and treatment algorithm. In: Friedman M, Jacobowitz O, editors. Sleep apnea and snoring E-Book: surgical and non-surgical therapy. Philadelphia (PA): Elsevier; 2008. p. 45.

17. Punjabi NM, Newman AB, Young TB, Resnick HE, Sanders MH. Sleep-disordered breathing and cardiovascular disease: an outcomebased definition of hypopneas. Am J Respir Crit Care Med. 2008 May;177(10):1150-5.

18. Kendzerska T, Gershon AS, Hawker G, Leung RS, Tomlinson G. Obstructive sleep apnea and risk of cardiovascular events and allcause mortality: a decade-long historical cohort study. PLoS Med. 2014 Feb;11(2):e1001599.

19. Aurora RN, Swartz R, Punjabi NM. Misclassification of OSA severity with automated scoring of home sleep recordings. Chest. 2015 Mar;147(3):719-27.

20. Kapoor M, Greenough G. Home sleep tests for Obstructive Sleep Apnea (OSA). J Am Board Fam Med. 2015 Jul-Aug;28(4):504-9.

21. Nerfeldt P, Aoki F, Friberg D. Polygraphy vs. polysomnography: missing OSAs in symptomatic snorers: a reminder for clinicians. Sleep Breath. 2014 May;18(2):297-303.

22. Watson NF. Health care savings: the economic value of diagnostic and therapeutic care for obstructive sleep apnea. J Clin Sleep Med. 2016 Aug;12(8):1075-7.

23. Scannone A, Tosta M, Suarez A, Otero L. Cephalometric and dental measures as diagnostic tools for the obstructive sleep apnea. J Sleep DisorTreat Care. 2017 Jan;6(4).

24. Torre C, Zaghi S, Camacho M, Capasso R, Liu SY. Hypopharyngeal evaluation in obstructive sleep apnea with awake flexible laryngoscopy: validation and updates to Cormack-Lehane and modified Cormack-Lehane scoring systems. Clin Otolaryngol. 2018 Jun; 43(3):823-7.

25. Kim JW, Kim J, Kim T, Lee K, Kim S, Bae M. Extraction of acoustic biomarkers from PSG to detect OSA. Sleep Med. 2017 Dec;40: e160.

26. Kim WY, Hong SN, Yang SK, Nam KJ, Lim KH, Hwang SJ, et al.The effect of body position on airway patency in obstructive sleep apnea: CT imaging analysis. Sleep Breath. 2019 Sep;23(3):911-6.

27. Huon LK, Liu SY, Shih TT, Chen YJ, Lo MT, Wang PC. Dynamic upper airway collapse observed from sleep MRI: BMI-matched severe and mild OSA patients. Eur Arch Otorhinolaryngol. 2016 Nov; 273(11):4021-6.

28. Soose RJ. Novel surgical approaches for the treatment of obstructive sleep apnea. Sleep Med Clin. 2016 Jun;11(2):189-202.

29. Kent DT, Rogers R, Soose RJ. Drug-induced sedation endoscopy in the evaluation of OSA patients with incomplete oral appliance therapy response. Otolaryngol Head Neck Surg. 2015 Aug;153(2): 302-7.

30. Vroegop AV,Vanderveken OM,Verbraecken JA. Drug-induced sleep endoscopy: evaluation of a selection tool for treatment modalities for obstructive sleep apnea. Respiration. 2020;99(5):451-7.

31. Glen JB. The development of 'Diprifusor': a TCI system for propofol.Anaesthesia. 1998 Apr;53 Suppl 1:13-21.

32. Hillman DR, Walsh JH, Maddison KJ, Platt PR, Kirkness JP, Noffsinger WJ, et al. Evolution of changes in upper airway collapsibility during slow induction of anesthesia with propofol. Anesthesiology. 2009 Jul;111(1):63-71.

33. Eastwood PR, Platt PR, Shepherd K, Maddison K, Hillman DR.
Collapsibility of the upper airway at different concentrations of propofol anesthesia. Anesthesiology. 2005 Sep;103(3):470-7.

34. Chattopadhyay U, Mallik S, Ghosh S, Bhattacharya S, Bisai S, Biswas $\mathrm{H}$. Comparison between propofol and dexmedetomidine on depth of anesthesia: a prospective randomized trial. J Anaesthesiol Clin Pharmacol. 2014 Oct;30(4):550-4.

35. Charakorn N, Kezirian EJ. Drug-induced sleep endoscopy. Otolaryngol Clin North Am. 2016 Dec;49(6):1359-72.

36. Croft CB, Pringle M. Sleep nasendoscopy: a technique of assessment in snoring and obstructive sleep apnoea. Clin Otolaryngol Allied Sci. 1991 Oct;16(5):504-9.

37. Kezirian EJ, Hohenhorst W, de Vries N. Drug-induced sleep endoscopy: the VOTE classification. Eur Arch Otorhinolaryngol. 2011Aug; 268(8):1233-6.

38. Friedman M, Ibrahim H, Bass L. Clinical staging for sleep-disordered breathing. Otolaryngol Head Neck Surg. 2002 Jul;127(1):13-21.

39. Iwanaga K, Hasegawa K, Shibata N, Kawakatsu K, Akita Y, Suzuki $\mathrm{K}$, et al. Endoscopic examination of obstructive sleep apnea syndrome patients during drug-induced sleep. Acta Otolaryngol Suppl. 2003;(550):36-40.

40. Vicini C, de Vito A, Benazzo M, Frassineti S, Campanini A, Frasconi $\mathrm{P}$, et al. The nose oropharynx hypopharynx and larynx (NOHL) classification: a new system of diagnostic standardized examination for OSAHS patients. Eur Arch Otorhinolaryngol. 2012 Apr;269(4): 1297-300.

41. Vroegop AV, Vanderveken OM, Boudewyns AN, Scholman J, Saldien V, Wouters K, et al. Drug-induced sleep endoscopy in sleepdisordered breathing: report on 1,249 cases. Laryngoscope. 2014 Mar;124(3):797-802.

42. Ravesloot MJ, de Vries N. One hundred consecutive patients undergoing drug-induced sleep endoscopy: results and evaluation. Laryngoscope. 2011 Dec;121(12):2710-6.

43. Vanderveken OM, Maurer JT, Hohenhorst W, Hamans E, Lin HS, Vroegop AV, et al. Evaluation of drug-induced sleep endoscopy as a patient selection tool for implanted upper airway stimulation for obstructive sleep apnea. J Clin Sleep Med. 2013 May;9(5):433-8.

44. Zhang P,Ye J, Pan C, Sun N, Kang D. The role of obstruction length and height in predicting outcome of velopharyngeal surgery. Otolaryngol Head Neck Surg. 2015 Jul;153(1):144-9.

45. Liu SY, Huon LK, Iwasaki T, Yoon A, Riley R, Powell N, et al. Efficacy of maxillomandibular advancement examined with drug-induced sleep endoscopy and computational fluid dynamics airflow modeling. Otolaryngol Head Neck Surg. 2016 Jan;154(1):189-95.

46. Lavie P. Rediscovering the importance of nasal breathing in sleep or, shut your mouth and save your sleep. J Laryngol Otol. 1987 Jun;101(6):558-63.

47. Busaba NY.The nose in snoring and obstructive sleep apnea. Curr Opin Otolaryngol Head Neck Surg. 1999 Feb;7(1):11.

48. Olsen KD, Kern EB, Westbrook PR. Sleep and breathing disturbance secondary to nasal obstruction. Otolaryngol Head Neck Surg. 1981 Sep-Oct;89(5):804-10.

49. Cole P, Haight JS. Mechanisms of nasal obstruction in sleep. Laryngoscope. 1984 Dec;94(12 Pt 1):1557-9.

50. VerseT, Maurer JT, PirsigW. Effect of nasal surgery on sleep-related breathing disorders. Laryngoscope. 2002 Jan;112(1):64-8.

51. Camacho M, Riaz M, Capasso R, Ruoff CM, Guilleminault C, Kushida CA, et al. The effect of nasal surgery on continuous positive airway pressure device use and therapeutic treatment pressures: a systematic review and meta-analysis. Sleep. 2015 Feb;38(2):279-86.

52. Trindade SH,Tagliarini JV, Elly I,Trindade K, Weber SA. Nasal septoplasty in patients with obstructive sleep apnea syndrome: effects on polysomnographic parameters. J Sleep Med Disord. 2017 Jun; 4(2):1077.

53. Elhabashy M, Abdelfatah A, Abdelaziz A, Omar H, Abdelwhab S. 
Effectiveness of septoplasty with or without inferior turbinate reduction in patients with obstructive sleep apnea. Eur Respir J. 2019; 54(Suppl 63):PA4163.

54. Friedman M, Salapatas AM. Algorithm for multilevel treatment: Friedman experience. In: Friedman M, Jacobowitz O, editors. Sleep apnea and snoring: surgical and non-surgical therapy. 2nd ed. Edinburgh: Elsevier; 2020. p. 120-6.

55. Abdelwahab M, Yoon A, OklandT, Poomkonsarn S, Gouveia C, Liu SY. Impact of distraction osteogenesis maxillary expansion on the internal nasal valve in obstructive sleep apnea. Otolaryngol Head Neck Surg. 2019 Aug;161(2):362-7.

56. Iwasaki T, Yoon A, Guilleminault C, Yamasaki Y, Liu SY. How does distraction osteogenesis maxillary expansion (DOME) reduce severity of obstructive sleep apnea? Sleep Breath. 2020 Mar;24(1): 287-96.

57. Liu SY, Guilleminault C, Huon LK, Yoon A. Distraction Osteogenesis Maxillary Expansion (DOME) for adult obstructive sleep apnea patients with high arched palate. Otolaryngol Head Neck Surg. 2017 Aug;157(2):345-8.

58. Yoon A, Guilleminault C, Zaghi S, Liu SY. Distraction Osteogenesis Maxillary Expansion (DOME) for adult obstructive sleep apnea patients with narrow maxilla and nasal floor. Sleep Med. 2020 Jan; 65:172-6.

59. Camacho M, Chang ET, Song SA, Abdullatif J, Zaghi S, Pirelli P, et al. Rapid maxillary expansion for pediatric obstructive sleep apnea: a systematic review and meta-analysis. Laryngoscope. $2017 \mathrm{Jul}$; 127(7):1712-9.

60. IwasakiT, Saitoh I,Takemoto Y, Inada E, Kanomi R, Hayasaki H, et al. Improvement of nasal airway ventilation after rapid maxillary expansion evaluated with computational fluid dynamics. Am J Orthod Dentofacial Orthop. 2012 Mar;141(3):269-78.

61. Iwasaki T, Takemoto Y, Inada E, Sato H, Suga H, Saitoh I, et al. The effect of rapid maxillary expansion on pharyngeal airway pressure during inspiration evaluated using computational fluid dynamics. Int J Pediatr Otorhinolaryngol. 2014 Aug;78(8):1258-64.

62. Villa MP, Malagola C, Pagani J, Montesano M, RizzoliA, Guilleminault C, et al. Rapid maxillary expansion in children with obstructive sleep apnea syndrome: 12-month follow-up. Sleep Med. 2007 Mar; $8(2): 128-34$.

63. Ishman SL, Ishii LE, Gourin CG. Temporal trends in sleep apnea surgery: 1993-2010. Laryngoscope. 2014;124(5):1251-8.

64. Camacho M, Nesbitt NB, Lambert E, Song SA, Chang ET, Liu SY, et al. Laser-assisted uvulopalatoplasty for obstructive sleep apnea: a systematic review and meta-analysis. Sleep. 2017 Mar;40(3).

65. Thaler ER, Rassekh CH, Lee JM, Weinstein GS, O'Malley BW Jr. Outcomes for multilevel surgery for sleep apnea: obstructive sleep apnea, transoral robotic surgery, and uvulopalatopharyngoplasty. Laryngoscope. 2016 Jan;126(1):266-9.

66. Lin HC, Friedman M, Chang HW, Gurpinar B. The efficacy of multilevel surgery of the upper airway in adults with obstructive sleep apnea/hypopnea syndrome. Laryngoscope. 2008 May;118(5):902-8.

67. Li HY. Palatal surgery for obstructive sleep apnea: from ablation to reconstruction. Sleep Med Clin. 2019 Mar;14(1):51-8.

68. Awad M, Gouveia C, Capasso R, Liu SY.Tonsillectomy and pharyngoplasty: tissue-preserving techniques. Atlas Oral Maxillofac Surg Clin North Am. 2019 Mar;27(1):17-22.

69. Camacho M, Zaghi S, Piccin O, Certal V. Expansion sphincter pharyngoplasty for obstructive sleep apnea: an update to the recent meta-analysis. Eur Arch Otorhinolaryngol. 2016 Sep;273(9):2857-8.

70. Vicini C, Hendawy E, Campanini A, Eesa M, BahgatA, AlGhamdi S, et al. Barbed reposition pharyngoplasty (BRP) for OSAHS: a feasibility, safety, efficacy and teachability pilot study: "we are on the giant's shoulders". Eur Arch Otorhinolaryngol. 2015 Oct;272(10): 3065-70.
71. Pang KP, Plaza G, Baptista J PM, O'Connor Reina C, Chan YH, Pang KA, et al. Palate surgery for obstructive sleep apnea: a 17-year meta-analysis. Eur Arch Otorhinolaryngol. 2018 Jul;275(7):1697-707.

72. Hsu YS, Jacobowitz O. Does sleep endoscopy staging pattern correlate with outcome of advanced palatopharyngoplasty for moderate to severe obstructive sleep apnea? J Clin Sleep Med. 2017 Oct; 13(10):1137-44.

73. Pang KP,Woodson BT. Expansion sphincter pharyngoplasty: a new technique for the treatment of obstructive sleep apnea. Otolaryngol Head Neck Surg. 2007 Jul;137(1):110-4.

74. Cahali MB, Formigoni GG, Gebrim EM, Miziara ID. Lateral pharyngoplasty versus uvulopalatopharyngoplasty: a clinical, polysomnographic and computed tomography measurement comparison. Sleep. 2004 Aug;27(5):942-50.

75. Woodson BT, Robinson S, Lim HJ. Transpalatal advancement pharyngoplasty outcomes compared with uvulopalatopharygoplasty. Otolaryngol Head Neck Surg. 2005 Aug;133(2):211-7.

76. Jacobowitz O. Algorithm for surgery: palatopharyngoplasty first and foremost. In: Friedman M, Jacobowitz O, editors. Sleep apnea and snoring: surgical and non-surgical therapy. 2nd ed. Edinburgh: Elsevier; 2020. p. 99-103.

77. Liu SY, Hutz MJ, Poomkonsarn S, Chang CP, Awad M, Capasso R. Palatopharyngoplasty resolves concentric collapse in patients ineligible for upper airway stimulation. Laryngoscope. 2020 Feb 28 [Epub]. https://doi.org/10.1002/lary.28595.

78. Campanini A, Canzi P, de Vito A, Dallan I, Montevecchi F, Vicini C. Awake versus sleep endoscopy: personal experience in 250 OSAHS patients. Acta Otorhinolaryngol Ital. 2010 Apr;30(2):73-7.

79. Friedman M, Soans R, Gurpinar B, Lin HC, Joseph N. Evaluation of submucosal minimally invasive lingual excision technique for treatment of obstructive sleep apnea/hypopnea syndrome. Otolaryngol Head Neck Surg. 2008 Sep;139(3):378-85.

80. Li HY, Lee LA, Kezirian EJ. Coblation endoscopic lingual lightening (CELL) for obstructive sleep apnea. Eur Arch Otorhinolaryngol. 2016 Jan;273(1):231-6.

81. Montevecchi F, Cammaroto G, Meccariello G, Hoff PT, Corso RM, Galletti C, et al. Transoral robotic surgery (TORS): a new tool for high risk tracheostomy decannulation. Acta Otorhinolaryngol Ital. 2017 Feb;37(1):46-50.

82. Cammaroto G, Meccariello G, Costantini M, Stomeo F, Hoff P, Montevecchi $\mathrm{F}$, et al. Trans-oral robotic tongue reduction for OSA: does lingual anatomy influence the surgical outcome? J Clin Sleep Med. 2018 Aug;14(8):1347-51.

83. Camacho M, Certal V, Capasso R. Comprehensive review of surgeries for obstructive sleep apnea syndrome. Braz J Otorhinolaryngol. 2013 Nov-Dec;79(6):780-8.

84. Justin GA, Chang ET, Camacho M, Brietzke SE. Transoral robotic surgery for obstructive sleep apnea: a systematic review and metaanalysis. Otolaryngol Head Neck Surg. 2016 May;154(5):835-46.

85. Vicini C, Montevecchi F, Meccariello G, Cammaroto G. Base of tongue surgery. In: Salman SO, editor. Modern management of obstructive sleep apnea. 1st ed. Cham: Springer; 2019. p. 59-68.

86. Chan JY, Wong EW, Tsang RK, Holsinger FC, Tong MC, Chiu PW, et al. Early results of a safety and feasibility clinical trial of a novel single-port flexible robot for transoral robotic surgery. Eur Arch Otorhinolaryngol. 2017 Nov;274(11):3993-6.

87. Chan JY, Holsinger FC, Liu S, Sorger JM, Azizian M, Tsang RK. Augmented reality for image guidance in transoral robotic surgery. J Robot Surg. 2020 Aug;14:579-83.

88. Song SA, Chang ET, Certal V, Del Do M, Zaghi S, Liu SY, et al. Genial tubercle advancement and genioplasty for obstructive sleep apnea: a systematic review and meta-analysis. Laryngoscope. 2017 Apr;127(4):984-92.

89. Riley RW, Powell NB, Guilleminault C. Obstructive sleep apnea 
syndrome: a review of 306 consecutively treated surgical patients. Otolaryngol Head Neck Surg. 1993 Feb;108(2):117-25.

90. Liu SY, Huon LK, Zaghi S, Riley R, Torre C. An accurate method of designing and performing individual-specific genioglossus advancement. Otolaryngol Head Neck Surg. 2017 Jan;156(1):194-7.

91. Cheng A. Genioglossus and genioplasty advancement. Atlas Oral Maxillofac Surg Clin North Am. 2019 Mar;27(1):23-8.

92. Oliven A, Odeh M, Geitini L, Oliven R, Steinfeld U, Schwartz AR, et al. Effect of coactivation of tongue protrusor and retractor muscles on pharyngeal lumen and airflow in sleep apnea patients. J Appl Physiol (1985). 2007 Nov;103(5):1662-8.

93. Dedhia RC, Strollo PJ, Soose RJ. Upper airway stimulation for obstructive sleep apnea: past, present, and future. Sleep. 2015 Jun; 38(6):899-906.

94. Strollo PJ Jr, Soose RJ, Maurer JT, deVries N, Cornelius J, Froymovich $\mathrm{O}$, et al. Upper-airway stimulation for obstructive sleep apnea. N Engl J Med. 2014 Jan;370(2):139-49.

95. Costantino A, Rinaldi V, Moffa A, Luccarelli V, Bressi F, Cassano M, et al. Hypoglossal nerve stimulation long-term clinical outcomes: a systematic review and meta-analysis. Sleep Breath. 2020 Jun;24(2): 399-411.

96. Hofauer B, Steffen A, Knopf A, Hasselbacher K, Heiser C.Adherence to upper-airway stimulation in the treatment of OSA. Chest. 2018 Feb;153(2):574-5.

97. Bohorquez D, Mahmoud AF, Yu JL, Thaler ER. Upper airway stimulation therapy and sleep architecture in patients with obstructive sleep apnea. Laryngoscope. 2020 Apr;130(4):1085-9.

98. Powell N, Riley RW.A surgical protocol for sleep disordered breathing. Oral Maxillofac Surg Clin North Am. 1995 May;7(3):345-56.

99. Riley RW, Powell NB. Maxillofacial surgery and obstructive sleep apnea syndrome. Otolaryngol Clin North Am. 1990 Aug;23(4): 809-26.

100. Riley RW, Powell NB, Guilleminault C. Maxillary, mandibular, and hyoid advancement for treatment of obstructive sleep apnea: a review of 40 patients. J Oral Maxillofac Surg. 1990 Jan;48(1):20-6.

101. Vicini C, Dallan I, Campanini A, de Vito A, Barbanti F, Giorgiomarrano $\mathrm{G}$, et al. Surgery vs ventilation in adult severe obstructive sleep apnea syndrome. Am J Otolaryngol. 2010 Jan-Feb;31(1):14-20.

102. Camacho M, Liu SY, Certal V, Capasso R, Powell NB, Riley RW. Large maxillomandibular advancements for obstructive sleep apnea: an operative technique evolved over 30 years. J Craniomaxillofac Surg. 2015 Sep;43(7):1113-8.

103. Liu SY, Awad M, Riley RW. Maxillomandibular advancement: contemporary approach at Stanford. Atlas Oral Maxillofac Surg Clin
North Am. 2019 Mar;27(1):29-36.

104. Boyd SB. Management of obstructive sleep apnea by maxillomandibular advancement. Oral Maxillofac Surg Clin North Am. 2009 Nov;21(4):447-57.

105. Liu SY, Huon LK, Powell NB, Riley R, Cho HG, Torre C, et al. Lateral pharyngeal wall tension after maxillomandibular advancement for obstructive sleep apnea is a marker for surgical success: observations from drug-induced sleep endoscopy. J Oral Maxillofac Surg. 2015 Aug;73(8):1575-82.

106. Chen YF, Ko EC, Zaghi S, Yoon A, Williams R, Riley R, et al. Optimizing mandibular sagittal split of large maxillomandibular advancements for obstructive sleep apnea: patient and surgical factors. Clin Oral Investig. 2020 Mar;24(3):1359-67.

107. Holty JE, Guilleminault C. Maxillomandibular advancement for the treatment of obstructive sleep apnea: a systematic review and meta-analysis. Sleep Med Rev. 2010 Oct;14(5):287-97.

108. Zaghi S, Holty JE, Certal V, Abdullatif J, Guilleminault C, Powell $\mathrm{NB}$, et al. Maxillomandibular advancement for treatment of obstructive sleep apnea: a meta-analysis. JAMA Otolaryngol Head Neck Surg. 2016 Jan;142(1):58-66.

109. Riley RW, Powell NB, Li KK, Troell RJ, Guilleminault C. Surgery and obstructive sleep apnea: long-term clinical outcomes. Otolaryngol Head Neck Surg. 2000 Mar;122(3):415-21.

110. Vigneron A,Tamisier R, Orset E, Pepin JL, Bettega G. Maxillomandibular advancement for obstructive sleep apnea syndrome treatment: long-term results. J Craniomaxillofac Surg. 2017 Feb;45(2): 183-91.

111. Boyd SB, Chigurupati R, Cillo JE Jr, Eskes G, Goodday R, Meisami $\mathrm{T}$, et al. Maxillomandibular advancement improves multiple healthrelated and functional outcomes in patients with obstructive sleep apnea: a multicenter study. J Oral Maxillofac Surg. 2019 Feb;77(2): 352-70.

112. Green KK, Kent DT, D’Agostino MA, Hoff PT, Lin HS, Soose RJ, et al. Drug-induced sleep endoscopy and surgical outcomes: a multicenter cohort study. Laryngoscope. 2019 Mar;129(3):761-70.

113. Soares D, Sinawe H, Folbe AJ, Yoo G, Badr S, Rowley JA, et al. Lateral oropharyngeal wall and supraglottic airway collapse associated with failure in sleep apnea surgery. Laryngoscope. 2012 Feb;122(2): 473-9.

114. Liu SY, Riley RW. Continuing the original Stanford Sleep Surgery Protocol from upper airway reconstruction to upper airway stimulation: our first successful case. J Oral Maxillofac Surg. 2017 Jul; 75(7):1514-8. 